\title{
Establishment of business incubation centers in universities; a step towards innovative business in health system
}

\author{
Sajida Mazhar ${ }^{1}$, Mohammad Bin Afsar Jan², Mishgan-e-Fatima ${ }^{3}$
}

Much needed services and resources for the progression of a business are presented by Business Incubation Centers (BIC) for beginner incubates. A successful business incubate would contribute positively in the region by forming original technologies and reducing unemployment. ${ }^{1,2}$ The set-up of Business Incubation Centers (BICs) is supported by Higher Education Commission (HEC) Pakistan which offers related services for young incubates, contributing to successful and freestanding companies in the country. A welcoming entrepreneurial ecosystem is much needed today. ${ }^{3}$ Coupled with local universities by bringing together incubates, students and universities, BIC can have an enormous impact on the economy. ${ }^{4}$ The main objectives of the BICs are to encourage self-employment among the young, commercializing research originating from universities, creating alliance between Industry and academia, and contributing to economic growth by employing \& forming viable firms. ${ }^{2}$

HEC has established thirty business incubation centers in public sector universities of major cities in Pakistan. These universities are imparting education in science and technology, agriculture, general universities and universities offering education in medical and allied health sciences. Among the thirty universities, BICs have been set up merely in two universities related to medicine and allied health sciences namely Khyber Medical University, Peshawar and Dow University of Health Sciences, Karachi. The focus of this editorial is to highlight this under studied area and center of attention for the startup of incubates from the universities offering education in health industry.

Equal regional distribution, an accessible industrial area, a dynamic research and development, accessible research facilities and availability of supportive business institutes are the decisive factors in choosing a university for the establishment of BIC. Many ground-breaking inventive projects enlisted on HEC's website are available for commercialization of research. All these types of activities are originating from engineering and technology universities and none of such activities have been observed from majority of the medical universities. Although integrating medicine with technology would positively impact the society many folds ${ }^{5}$,yet, it appears to be a ground unfamiliar by most of the faculty working in medical universities. ${ }^{2}$ Assessing comments of medical faculty confirms their estrangement regarding the new services offered in the form of BICs in the universities. ${ }^{2}$ There is a lack of knowledge among the faculty concerning BIC or perhaps most of them appear to have limited knowledge, enthusiasm and incentives amongst faculty associate with medical education. Much work has to be done in encouraging medical faculty who has an excellent potential to positive contributions in incubating ideas. Informal surveys and observations that we conducted further illustrated the aforementioned points and confirm inadequate knowledge of faculty and students regarding BICs and its aims of formation. BICs in health industry appear to be a foreign ground passing unnoticed by faculty today. One can find many startups emerging in the field of health worldwide from internet sources cited as 'Top 15 Health Startup Incubators in the US' and '12 healthcare startup incubators and accelerators to know' etc. ${ }^{6}$ In Pakistan many innovative business projects originating from the fields of IT, environmental sciences, agriculture, engineering technology have been registered by HEC and are ready for commercialization.

Khyber Medical University Business Incubation Center (KUBIC) and Impact Dynamics together conducted a successful competition namely IDEA-CUP-19 focusing on health startups. KUBIC was the first center in Pakistan to provide an effective platform interconnecting investors and commercial industries inviting multiple incubates across the province to bring forth innovative ideas in the field of health. The future of business incubation appears bright as there are rich opportunities of research today despite the challenges they face as analyzed by past three decades of emerging practice.

\section{REFERENCES}

1. Khieng S, Mason S, Lim S. Innovation and Entrepreneurship Ecosystem in Cambodia: The Roles of Academic Institutions. 2019.

2. Zabalawi I, Toglaw S, Alsarheed M. The Role of Faculty Members in Building an Entrepreneurship Culture in Higher Education: The Case of the Australian
College of Kuwait. Higher Education in the Arab World. Springer; 2020:337-356.

3. Graft A, Joseph J, Joshi N, Paarmann E, Ruchismita R. Health horizons 2021: emerging opportunities for social entrepreneurs in india. 2014;

4. Heinonen H. Business Incubation Service for social and health care sector
1996-2006. Laurea-ammattikorkeakoulun julkaisusarja B. 1996;17

5. Maheu M, Whitten P, Allen A. E-Health, Telehealth, and Telemedicine: a guide to startup and success. John Wiley \& Sons; 2002.

6. Pal M. Top 15 Health Startup Incubators in the US. Sep 4, 2019 2020; 